\title{
Impairment of Electron Transfer Chain Induced by Acute Carnosine Administration in Skeletal Muscle of Young Rats
}

\author{
José Roberto Macarini, ${ }^{1}$ Soliany Grassi Maravai, ${ }^{1}$ \\ José Henrique Cararo, ${ }^{1}$ Nádia Webber Dimer, ${ }^{1}$ Cinara Ludvig Gonçalves, ${ }^{2}$ \\ Luiza Wilges Kist, ${ }^{3,4,5}$ Mauricio Reis Bogo, ${ }^{3,4,5}$ Patrícia Fernanda Schuck, ${ }^{1}$ \\ Emilio Luiz Streck, ${ }^{2,5}$ and Gustavo Costa Ferreira ${ }^{6}$ \\ ${ }^{1}$ Laboratório de Erros Inatos do Metabolismo, Programa de Pós-Graduação em Ciências da Saúde, Unidade Acadêmica de \\ Ciências da Saúde, Universidade do Extremo Sul Catarinense, 88801-600 Criciúma, SC, Brazil \\ ${ }^{2}$ Laboratório de Bioenergética, Programa de Pós-Graduação em Ciências da Saúde, Unidade Acadêmica de \\ Ciências da Saúde, Universidade do Extremo Sul Catarinense, 88806-000 Criciúma, SC, Brazil \\ ${ }^{3}$ Laboratório de Biologia Genômica e Molecular, Faculdade de Biociências, Pontifícia Universidade Católica do Rio Grande do Sul, \\ 90619-900 Porto Alegre, RS, Brazil \\ ${ }^{4}$ Programa de Pós-Graduação em Medicina e Ciências da Saúde, Pontifícia Universidade Católica do Rio Grande do Sul, \\ 90619-900 Porto Alegre, RS, Brazil \\ ${ }^{5}$ Instituto Nacional de Ciência e Tecnologia Translacional em Medicina (INCT-TM), 90035-003 Porto Alegre, RS, Brazil \\ ${ }^{6}$ Laboratório de Neuroquímica, Instituto de Biofísica Carlos Chagas Filho, Universidade Federal do Rio de Janeiro, \\ Avenida Carlos Chagas Filho 373, Cidade Universitária, Ilha do Fundão, 21941-902 Rio de Janeiro, RJ, Brazil \\ Correspondence should be addressed to Gustavo Costa Ferreira; gustavolhe@gmail.com
}

Received 10 February 2014; Revised 6 April 2014; Accepted 7 April 2014; Published 4 May 2014

Academic Editor: Marcos Roberto de Oliveira

Copyright (C) 2014 José Roberto Macarini et al. This is an open access article distributed under the Creative Commons Attribution License, which permits unrestricted use, distribution, and reproduction in any medium, provided the original work is properly cited.

Serum carnosinase deficiency is an inherited disorder that leads to an accumulation of carnosine in the brain tissue, cerebrospinal fluid, skeletal muscle, and other tissues of affected patients. Considering that high levels of carnosine are associated with neurological dysfunction and that the pathophysiological mechanisms involved in serum carnosinase deficiency remain poorly understood, we investigated the in vivo effects of carnosine on bioenergetics parameters, namely, respiratory chain complexes (I-III, II, and IIIII), malate dehydrogenase, succinate dehydrogenase, and creatine kinase activities and the expression of mitochondrial-specific transcription factors (NRF-1, PGC-1 $\alpha$, and TFAM) in skeletal muscle of young Wistar rats. We observed a significant decrease of complexes I-III and II activities in animals receiving carnosine acutely, as compared to control group. However, no significant alterations in respiratory chain complexes, citric acid cycle enzymes, and creatine kinase activities were found between rats receiving carnosine chronically and control group animals. As compared to control group, mRNA levels of NRF-1, PGC-1 $\alpha$, and TFAM were unchanged. The present findings indicate that electron transfer through the respiratory chain is impaired in skeletal muscle of rats receiving carnosine acutely. In case these findings are confirmed by further studies and ATP depletion is also observed, impairment of bioenergetics could be considered a putative mechanism responsible for the muscle damage observed in serum carnosinasedeficient patients.

\section{Introduction}

Carnosine ( $\beta$-alanyl-L-histidine) is an imidazole dipeptide abundant in skeletal muscle, as well as in central nervous system [1], cardiac muscle, kidney, stomach, and olfactory bulbs $[2,3]$ of most animals. Physiological levels of carnosine may reach up to $20 \mathrm{mM}$ in muscle tissues [4], and its biological role remains unclear. Carnosine of human diet 
is uptaken by intestinal proton-coupled peptide transporter, namely, human $\mathrm{H}^{+}$/peptide cotransporter 1 (hPEPT1) [5]. This dipeptide is synthesized starting from its component amino acids histidine and $\beta$-alanine, by enzyme carnosine synthetase (EC 6.3.2.11). On the other hand, the clearance of carnosine is essentially due to the hydrolytic action of a metalloprotease, the carnosinase [6]. This enzyme exists in two isoforms. The secreted form, namely, serum carnosinase (EC 3.4.13.20), is found primarily in serum, as well as in brain and cerebrospinal fluid. The cytosolic form, tissue carnosinase (EC 3.4.13.3), is present in several tissues, including liver, kidney, and spleen, but not skeletal muscle [7]. Both carnosinase isoforms differ not only in distribution and molecular weight, but also in substrate specificity.

Serum carnosinase deficiency (OMIM number 212200) results in accumulation of carnosine and related compounds homocarnosine and anserine in plasma $(20-30 \mu \mathrm{mol} / \mathrm{mL}$ serum), urine [8], and tissues of affected patients. The clinical presentation includes tremor, myoclonic seizures, hypotonia, psychomotor retardation, and inability to social relationship $[9,10]$. The coexistence of this rare enzymatic deficiency and a deletion in the long arm of chromosome 18 in a child was reported, suggesting the localization of serum carnosinase gene [11]. Currently, there are no reports of effective treatment for the disease. According to Willi and colleagues [11], diet restricted in meat ameliorates the clinical symptoms, but it does not fully eliminate them. Due to rarity of the disease, the mechanisms of tissue damage observed in affected subjects are still to be unraveled.

Such patients accumulate carnosine in tissues and body fluids and present a wide range of muscle alterations. In this scenario, the present work aimed to investigate the influence of acute and chronic carnosine administration on some parameters of energy homeostasis in skeletal muscle of young rats, namely, respiratory chain complexes (I-III, II, and II-III), citric acid cycle enzymes (succinate dehydrogenase and malate dehydrogenase), and creatine kinase activities, as well as the expression of transcription factors (NRF-1, PGC$1 \alpha$, and TFAM) related to mitochondrial biogenesis.

\section{Materials and Methods}

2.1. Animals. Twenty-four male Wistar rats (250-300 g; age 30 days) obtained from the Central Animal House of Universidade do Extremo Sul Catarinense, Santa Catarina, Brazil, were caged in groups of six, provided with ad libitum commercial rat chow and water, and maintained on a $12 \mathrm{~h}$ light-dark cycle at a temperature of $23 \pm 1^{\circ} \mathrm{C}$. The animals were randomly divided into four groups $(n=6)$ : sham (saline) and carnosine (100 mg/kg of body weight) acute and chronic groups. All studies were performed in accordance with the National Institutes of Health guidelines and EU Directive 2010/63/EU for animal experiments and with the approval of the Ethics Committee of Universidade do Extremo Sul Catarinense (Protocol number 67/2012).

2.2. Carnosine Administration. Male Wistar rats were divided into acute and chronic treatment groups. In acute administration, the animals received a single dose of carnosine $(100 \mathrm{mg} / \mathrm{kg}$ of body weight) administered intraperitoneally. Twenty-four hours after administration, the rats were euthanized. In the chronic administration, the animals received a daily dose of the dipeptide $(100 \mathrm{mg} / \mathrm{kg}$ of body weight) administered intraperitoneally for five days, and one hour after the last injection the rats were euthanized by decapitation without anesthesia, and the skeletal muscle was removed for subsequent biochemical analysis. The animals of control group were subjected to similar experimental conditions as carnosine group, but received vehicle $(\mathrm{NaCl} 0.9 \%)$ instead of carnosine.

2.3. Complexes I-CoQ-III Activities. NADH: oxidoreductase cytochrome $c$ (complexes I-III) activity was determined according to Schapira and colleagues [14], by the determination of cytochrome $c$ reduction at $\lambda=550 \mathrm{~nm}$. Results are expressed as $\mathrm{nmol} \cdot \mathrm{min}^{-1} \cdot \mathrm{mg}$ protein $^{-1}$.

2.4. Complex II Activity. Succinate: 2,6-dichloroindophenoloxidoreductase (complex II) activity was evaluated using the method described by Fischer et al. [15]. Complex II activity was measured by following the decrease in absorbance, due to the reduction of 2,6-dichloroindophenol at $\lambda=600 \mathrm{~nm}$. Results are expressed as $\mathrm{nmol} \cdot \mathrm{min}^{-1} \cdot \mathrm{mg}$ protein $^{-1}$.

2.5. Complexes II-III Activities. Succinate: cytochrome c oxidoreductase (complexes II-III) activity was determined according to Fischer et al. [15]. Complexes II-III activities were measured by cytochrome $c$ reduction, using succinate as substrate at $\lambda=550 \mathrm{~nm}$. Results are expressed as $\mathrm{nmol} \cdot \mathrm{min}^{-1} \cdot \mathrm{mg}$ protein ${ }^{-1}$.

2.6. Creatine Kinase Activity. Creatine kinase (EC 2.7.3.2) activity was measured in total homogenates using the method described by Hughes [16] with slight modifications [17]. Results are expressed as $\mu \mathrm{mol}$ creatine $\cdot \mathrm{min}^{-1} \cdot \mathrm{mg}_{\text {protein }}{ }^{-1}$.

2.7. Succinate Dehydrogenase Activity. Succinate dehydrogenase (EC 1.3.99.1) activity was determined in homogenates according to Fischer et al. [15]. Results are expressed as $\mathrm{nmol} \cdot \mathrm{min}^{-1} \cdot \mathrm{mg}$ protein ${ }^{-1}$.

2.8. Malate Dehydrogenase Activity. Malate dehydrogenase (EC 1.1.1.37) activity was evaluated according to Kitto [18] by following the reduction of $\mathrm{NADH}$ at wavelengths of excitation and emission of 340 and $466 \mathrm{~nm}$, respectively. Results were calculated as $\mathrm{nmol} \cdot \mathrm{min}^{-1} \cdot \mathrm{mg}_{\text {protein }}{ }^{-1}$.

2.9. Expression of Mitochondrial-Specific Transcription Factors. Transcript abundance of key factors involved in mitochondrial biogenesis was evaluated by quantitative real-time RT-PCR (RT-qPCR). Total RNA was isolated with Trizol reagent (Invitrogen, Carlsbad, CA, USA) in accordance with the manufacturer's instructions. The total RNA was quantified by spectrophotometry (A260/280 nm) and after treated with deoxyribonuclease I (Invitrogen) to eliminate genomic 


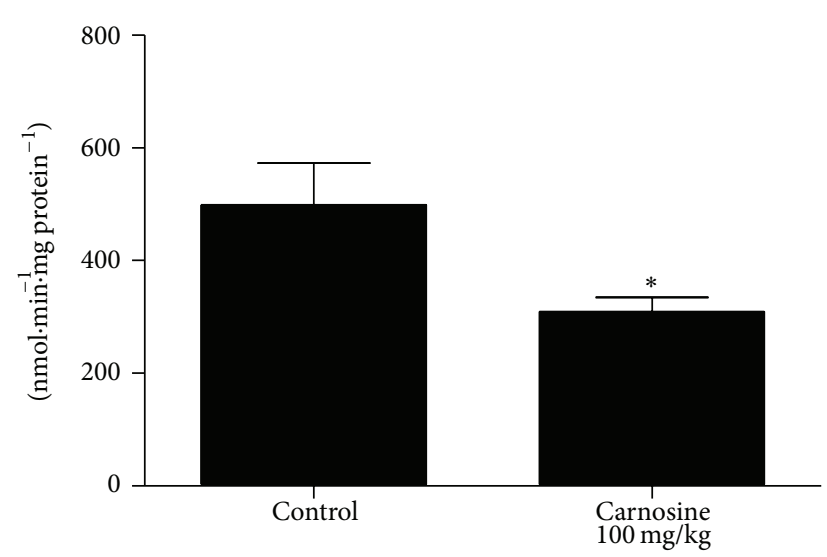

(a)

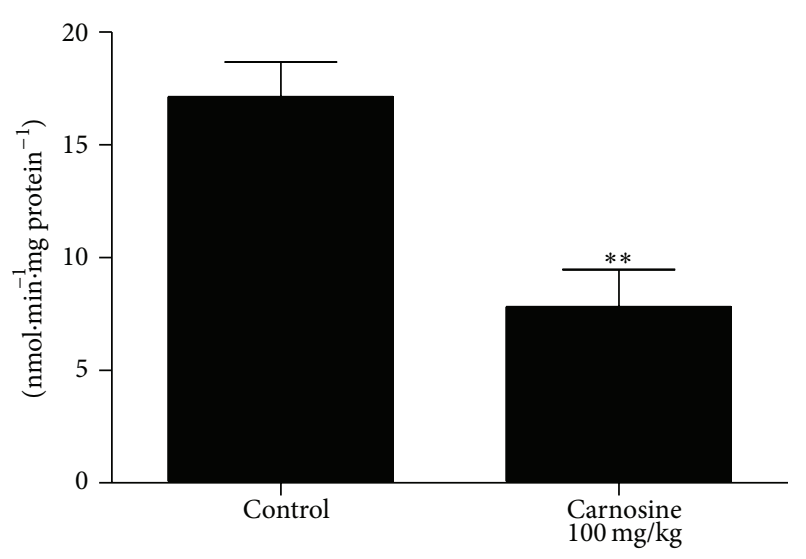

(b)

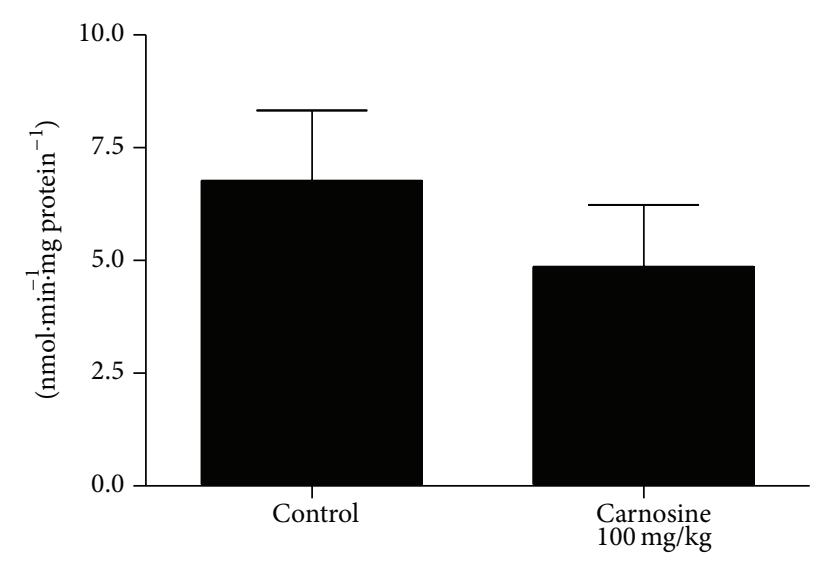

(c)

FIGURE 1: Effect of acute carnosine administration on respiratory chain complexes I-III (a), II (b), and II-III (c) activities in skeletal muscle of young rats. Data represent mean \pm S.E.M. for four to six independent animals performed in duplicate and are expressed in $\mathrm{nmol} \mathrm{min}{ }^{-1} \mathrm{mg}$ protein $^{-1} .{ }^{*} P<0.05,{ }^{* *} P<0.01$ compared to control group (Student's $t$-test).

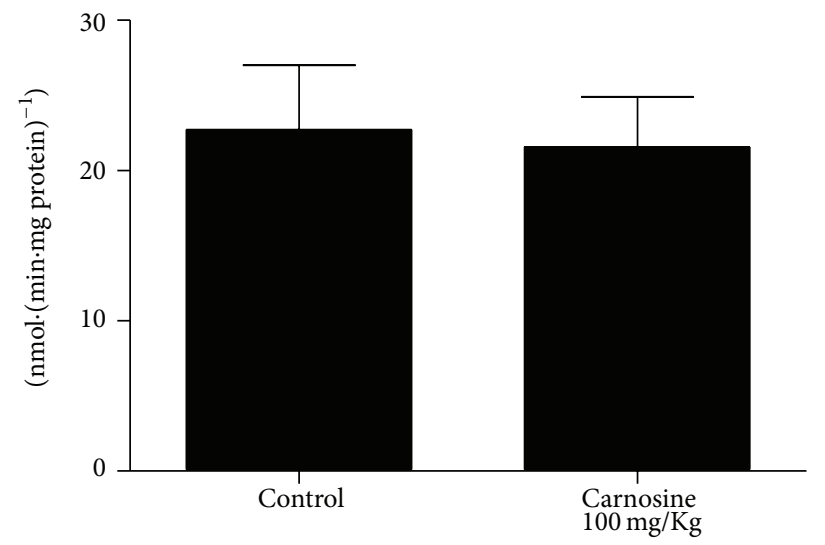

(a)

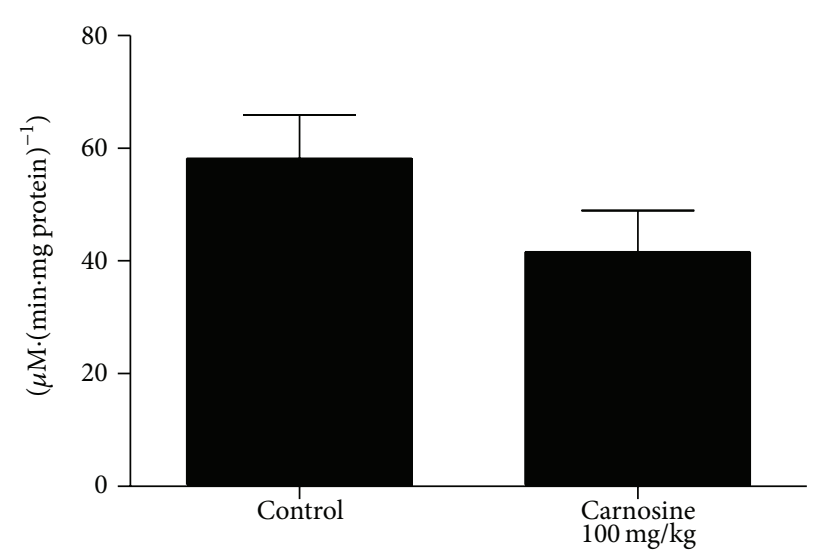

(b)

FiguRE 2: Effect of acute carnosine administration on citric acid cycle enzymes succinate dehydrogenase (a) and malate dehydrogenase (b) activities in skeletal muscle of young rats. Data are mean \pm S.E.M. for six independent animals performed in duplicate and are expressed in $\mathrm{nmol} \mathrm{min}^{-1} \mathrm{mg}$ protein ${ }^{-1}$. No significant differences between groups were detected (Student's $t$-test). 
TABLE 1: Primer sequences for RT-qPCR experiments included in the study.

\begin{tabular}{|c|c|c|}
\hline Gene & Forward primer & Reverse primer \\
\hline $\operatorname{Gapd}^{\mathrm{a}}$ & 5'-GCTAAGCAGTTGGTGGTGCA-3' $^{\prime}$ & $5^{\prime}$-TCACCACCATGGAGAAGGC-3' \\
\hline$H p r t 1^{\mathrm{a}}$ & $5^{\prime}$-GCAGACTTTGCTTTCCTTGG-3' & 5'-GCAGACTTTGCTTTCCTTGG-3' \\
\hline$N R F-1^{\mathrm{b}}$ & $5^{\prime}$-TTACTCTGCTGTGGCTGATGG-3' & $5^{\prime}$-CCTCTGATGCTTGCGTCGTCT-3' \\
\hline$P G C-1 \alpha^{\mathrm{c}}$ & $5^{\prime}$-CGTTACACCTGTGACGCTTTCGCTG-3' & $5^{\prime}$-CATACTTGCTCTTGGTGGAAGCAGG-3' \\
\hline$T F A M^{\mathrm{c}}$ & 5'-AATTGAAGCTTGTAAATCAGGCTTGG-3' & $5^{\prime}$-CGGATGAGATCACTTCGCCCAAC-3' \\
\hline
\end{tabular}

According to ${ }^{a}$ Bonefeld et al., 2008 [12]; ' Zhang et al., 2012 [13]; ${ }^{\text {c }}$ esigned by authors.

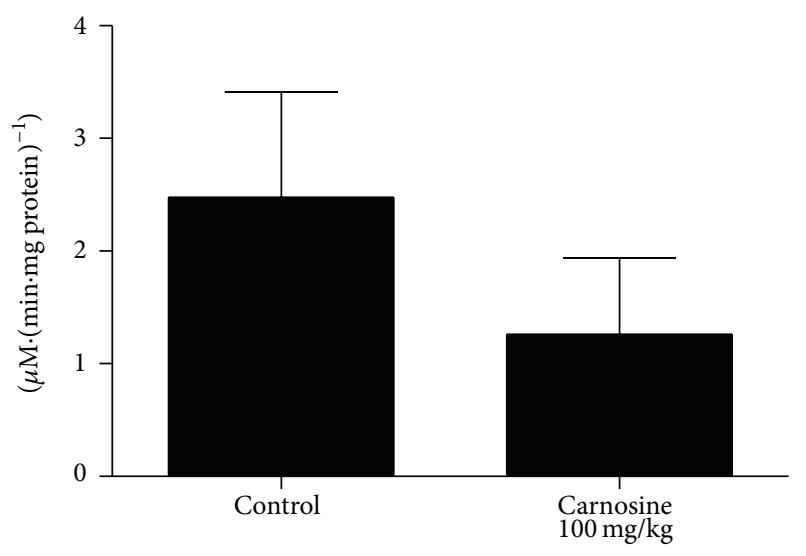

FIGURE 3: Effect of acute carnosine administration on creatine kinase activity in skeletal muscle of young rats. Data are mean \pm S.E.M. for six independent animals performed in duplicate and are expressed in $\mu \mathrm{mol}$ creatine $\mathrm{min}^{-1} \mathrm{mg}$ protein ${ }^{-1}$. No significant difference between groups was observed (Student's $t$-test).

DNA contamination in accordance with the manufacturer's instructions. The cDNA was synthesized with ImProm-II Reverse Transcription System (Promega) from $1 \mu \mathrm{g}$ total RNA, following the manufacturer's instruction. Quantitative PCR was performed using SYBR Green I (Invitrogen) to detect double-strand cDNA synthesis. Reactions were done in a volume of $25 \mu \mathrm{L}$ using $12.5 \mu \mathrm{L}$ of diluted cDNA, containing a final concentration of $0.2 x$ SYBR Green I (Invitrogen), $100 \mu \mathrm{M}$ dNTP, $1 \mathrm{x}$ PCR Buffer, $3 \mathrm{mM} \mathrm{MgCl}, 2,0.25 \mathrm{U}$ Platinum Taq DNA Polymerase (Invitrogen), $0.5 \mathrm{M}$ of betaine (for Gapd [12], Hprt1 [12], PGC-1 $\alpha$, and TFAM), 2\% of the reaction of DMSO (for NRF-1 [13]), and $200 \mathrm{nM}$ of each of reverse and forward primers (Table 1). The PCR cycling conditions were an initial polymerase activation step for $5 \mathrm{~min}$ at $95^{\circ} \mathrm{C}$, 40 cycles of $15 \mathrm{~s}$ at $95^{\circ} \mathrm{C}$ for denaturation, $35 \mathrm{~s}$ at $60^{\circ} \mathrm{C}$ for annealing, and $15 \mathrm{~s}$ at $72^{\circ} \mathrm{C}$ for elongation. At the end of cycling protocol, a melting-curve analysis was included and fluorescence measured from 60 to $99^{\circ} \mathrm{C}$ and showed in all cases one single peak. Gapd and Hprt1 were used as reference genes for normalization. Relative expression levels were determined with 7500 and 7500 Fast Real-Time PCR Systems Software v.2.0.6 (Applied Biosystems). The efficiency per sample was calculated using LinRegPCR 2012.3 Software (http://LinRegPCR.nl/). Relative mRNA expression levels were determined using the $2^{-\Delta \Delta \mathrm{CT}}$ method.
2.10. Protein Determination. Protein was measured by Lowry and colleagues [19] method, using bovine serum albumin as standard.

2.11. Statistical Analysis. Results are presented as mean \pm standard error of mean (S.E.M.). Assays were performed in duplicate and the mean or median was used for statistical analysis. Data was analyzed using Student's $t$-test. Differences between groups were rated significant at $P \leq 0.05$. All analyses were carried out in an IBM-compatible PC computer using the Statistica version 7 software. Molecular data were expressed as means \pm S.E.M. and analyzed by Student's $t$ test for unpaired samples considering $P<0.05$ as statistical significance.

\section{Results}

3.1. Energy Metabolism Is Impaired by Acute Carnosine Administration in Skeletal Muscle of Young Rats. Initially, we tested the influence of acute carnosine administration. In such condition, we observed a statistically significant decrease of complexes I-III $\left[t_{(10)}=2.41 ; P<0.05\right.$ ] (Figure 1(a)) and II $\left[t_{(8)}=3.86 ; P<0.01\right]$ (Figure 1(b)) activities in treated animals, as compared to control group rats. Furthermore, the complexes II-III $\left[t_{(10)}=0.918 ; P>\right.$ $0.05]$ (Figure $1(\mathrm{c})$ ), succinate dehydrogenase $\left[t_{(10)}=0.211 ; P>\right.$ $0.05]$ (Figure 2(a)), malate dehydrogenase $\left[t_{(10)}=1.56 ; P>\right.$ $0.05]$ (Figure 2(b)), and creatine kinase $\left[t_{(10)}=1.05 ; P>0.05\right]$ (Figure 3) activities were not significantly different between groups. However, we identified a nonsignificant decrease in complexes II-III and malate dehydrogenase activities in animals that received carnosine, as compared to control rats (Figures 1(c) and 2(b), resp.).

\subsection{Chronic Carnosine Administration Does Not Affect Energy} Metabolism in Rat Skeletal Muscle. The biochemical parameters following chronic carnosine administration were also evaluated. We detected no statistically significant difference in complexes I-III $\left[t_{(9)}=-0.169 ; P>0.05\right]$ (Figure 4(a)), II $\left[t_{(9)}=-0.383 ; P>0.05\right]$ (Figure 4(b)), II-III $\left[t_{(9)}=-0.289\right.$; $P>0.05]$ (Figure 4(c)), succinate dehydrogenase $\left[t_{(10)}=\right.$ $0.274 ; P>0.05]$ (Figure 5(a)), malate dehydrogenase $\left[t_{(10)}\right.$ $=0.374 ; P>0.05]$ (Figure 5(b)), and creatine kinase $\left[t_{(10)}=\right.$ $-0.113 ; P>0.05$ ] (Figure 6) activities between groups in rat skeletal muscle. However, it was observed that there is a trend 


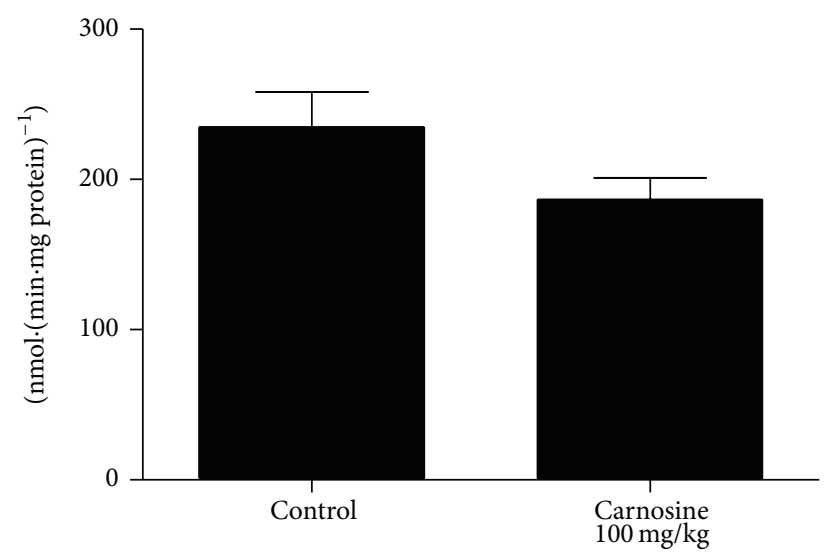

(a)

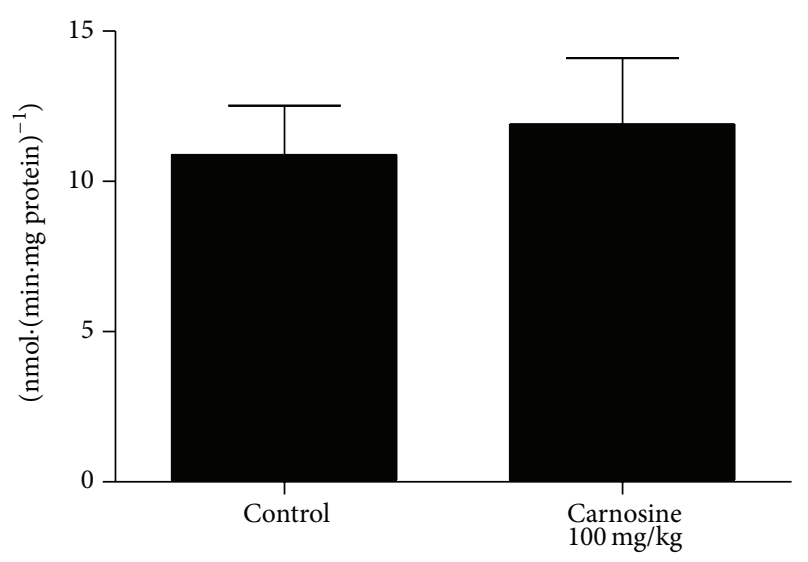

(b)

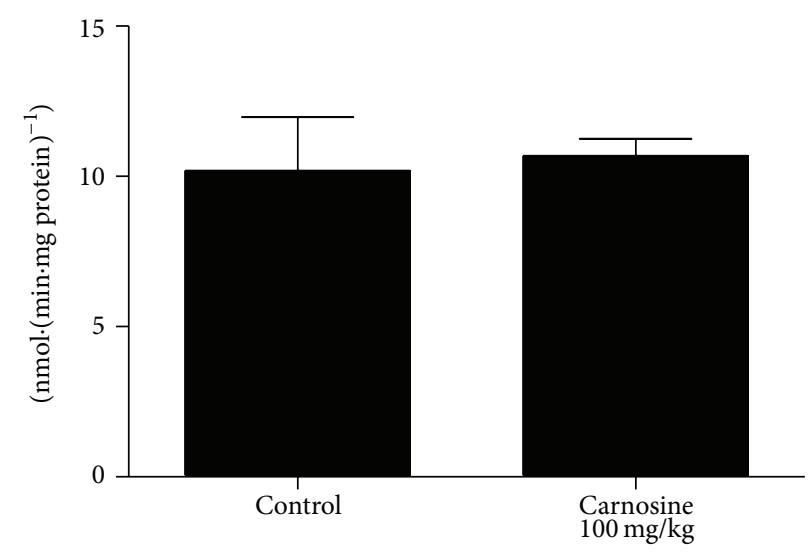

(c)

FIGURE 4: Effect of chronic carnosine administration on respiratory chain complexes I-III (a), II (b), and II-III (c) activities in skeletal muscle of young rats. Data are mean \pm S.E.M. for five to six independent animals performed in duplicate and are expressed in $\mathrm{nmol} \mathrm{min}{ }^{-1} \mathrm{mg}$ protein $^{-1}$. No significant difference between groups was detected (Student's $t$-test).

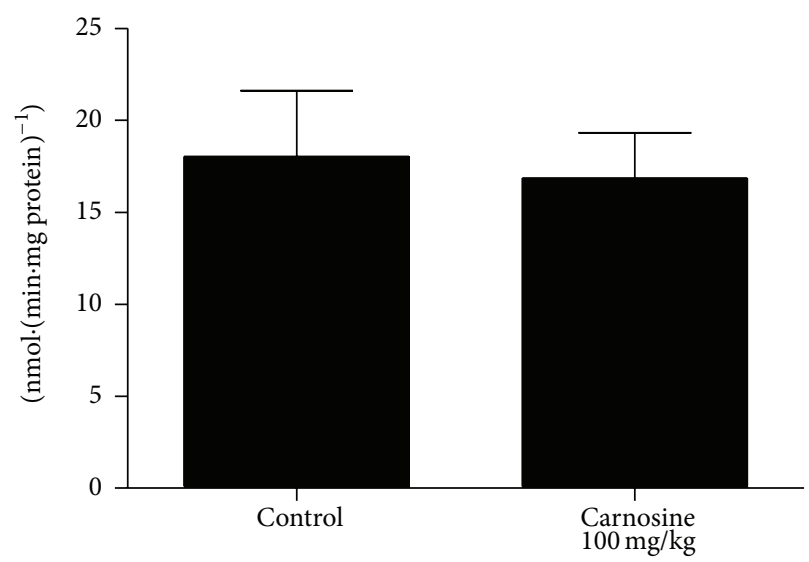

(a)

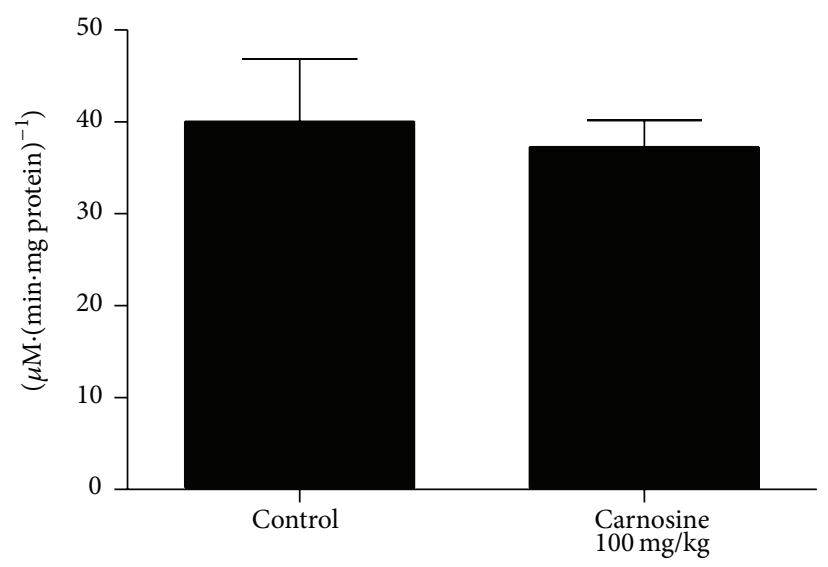

(b)

FIGURE 5: Effect of chronic carnosine administration on citric acid cycle enzymes succinate dehydrogenase (a) and malate dehydrogenase (b) activities in skeletal muscle of young rats. Data are mean \pm S.E.M. for six independent animals performed in duplicate and are expressed in $\mathrm{nmol} \mathrm{\textrm {min } ^ { - 1 } \mathrm { mg } \text { protein }}{ }^{-1}$. No significant difference between groups was observed (Student's $t$-test). 


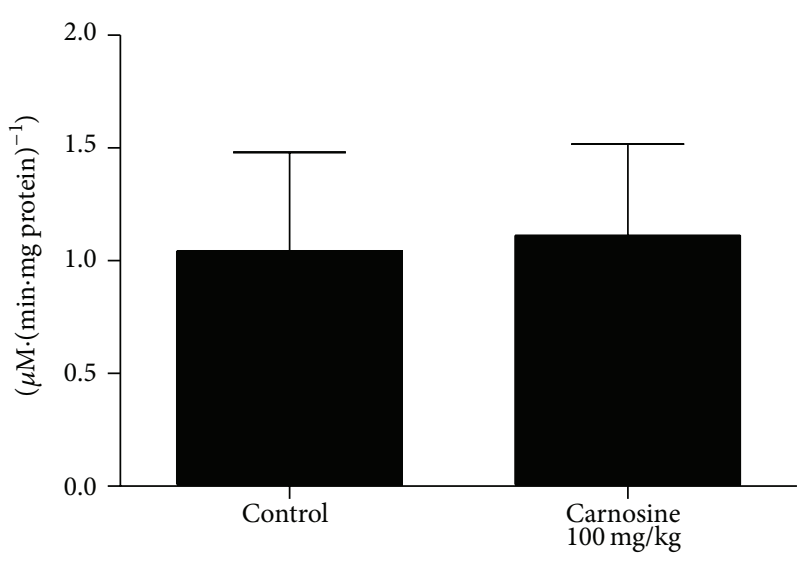

FIGURE 6: Effect of chronic carnosine administration on creatine kinase activity in skeletal muscle of young rats. Data are mean \pm S.E.M. for six independent animals performed in duplicate and are expressed in $\mu \mathrm{mol}$ creatine $\mathrm{min}^{-1} \mathrm{mg}$ protein ${ }^{-1}$. No significant difference between groups was detected (Student's $t$-test).

of decrease of complexes I-III activities in animals receiving carnosine, as compared to control rats (Figure 4(a)).

3.3. Mitochondrial Biogenesis. Transcript abundance of key factors involved in mitochondrial biogenesis was evaluated by RT-qPCR in skeletal muscle of animals receiving carnosine acutely (Figure 7) or chronically (Figure 8). As compared to control groups, mRNA levels of NRF-1, PGC-1 $\alpha$, and TFAM in the animals receiving carnosine under either regimen of administration were unchanged.

\section{Discussion}

In skeletal muscle tissue of most vertebrates and some invertebrates, the imidazole dipeptide carnosine is synthesized from histidine and $\beta$-alanine by the ATP-dependent enzyme carnosine synthetase [20]. The biological roles of carnosine and related dipeptides in skeletal muscle remain uncertain, although it is possible that they act as proton buffering agents [4]. Furthermore, there are a growing number of evidences related to carnosine effects on metabolism. Aside from its antioxidant activity [21, 22], carbonyl-scavenger ability has been assigned to carnosine [23] and other imidazole dipeptides [24]. Many of carbonyl compounds are metabolic toxic by-products and, in the bulk of tissues, they are detoxified by oxidoreductases. These enzymes catalyze the oxidation or reduction of aldehydes, or its conjugation with low molecular weight amines and thiols, such as reduced glutathione and imidazole dipeptides [25]. Carnosine was also shown to react with methylglyoxal, a toxic metabolic by-product of glycolysis, as well as to inhibit cancer and aging mechanisms [26] and the cellular respiration regulatory complex mTOR [27], and activate the gluconeogenic enzyme, fructose-1,6bisphosphatase [28].

It was also shown that carnosine intake significantly diminishes the activity and mRNA expression of malic enzyme, fatty acid synthase, 3-hydroxy-3-methylglutaryl coenzyme A (HMG-CoA) reductase, sterol regulatory element-binding proteins (SREBP-1c), and SREBP-2 in mice that consumed high saturated fat diet [29]. Carnosine was able to inhibit $\mathrm{Zn}^{2+}$-induced death of GT1-7 neurons through the inhibition of GADD34, $p 8$ (endoplasmic reticulum stress-related genes), and Arc (calcium-related gene) expression [30]. Finally, Asperger and colleagues [31], through a proteomics study with glioblastoma cells receiving carnosine, detected 31 proteins expressed differentially under the influence of dipeptide, including BCL2-associated athanogene 2 and von Hippel-Lindau binding protein 1.

In the present study, we observed a statistically significant decrease of complexes I-III and II activities in animals receiving carnosine acutely, compared to control group rats. Additionally, we detected no significant difference in complexes II-III, citric acid cycle enzymes, and creatine kinase activities between groups. Finally, we were also not able to find any significant alteration of respiratory chain complexes, citric acid cycle enzymes, and creatine kinase activities. Since several evidences suggest that many of the physiological effects of carnosine administration initiate at transcriptional level, as shown by changes in mRNA levels of HIF- $\alpha$ [32], runt-related transcription factor-2/core binding factor alpha-1 (RUNX2/Cbf $\alpha 1$ ), Sox9 [33], Hsp70, and SOD2 [34], mitochondrial biogenesis could explain these findings. Nevertheless, it was found that mRNA levels of NRF-1, PGC$1 \alpha$, and TFAM in skeletal muscle of rats receiving carnosine acutely or chronically were similar to those measured in control animals.

Our finding showing that the malate dehydrogenase activity presented no statistically significant difference between groups in both treatments corroborates, at least in part, a literature report. It was found that a patient with serum carnosinase deficiency exhibited malate dehydrogenase and lactate dehydrogenase activities within normal limits in liver, kidney, and spleen specimens, despite the fact that patients with this disorder present high levels of carnosine in their plasma (carnosinemia) [8].

We also observed that succinate dehydrogenase activity in skeletal muscle of carnosine group was not significantly different from those in control group, in animals subjected to either acute or chronic carnosine administration. On the other hand, a literature report showed that rats chronically intoxicated with ethanol presented reduced activity of some hepatic enzymes, including succinate dehydrogenase [35]. It was also showed in the same study that carnosine load for two weeks previously or simultaneously with ethanol intoxication prevents or reverses the toxicity of such alcohol on this enzyme activity.

It should be emphasized that, in skeletal muscle of rats receiving carnosine acutely, a statistically significant decrease in complexes I-III and II activities was identified, as well as a trend of decrease in complexes II-III activities, relatively to control group. However, rats receiving carnosine chronically showed only a trend of decrease in complexes I-III activities in skeletal muscle, as compared to control group, whereas the other complexes activities were not different between groups. 


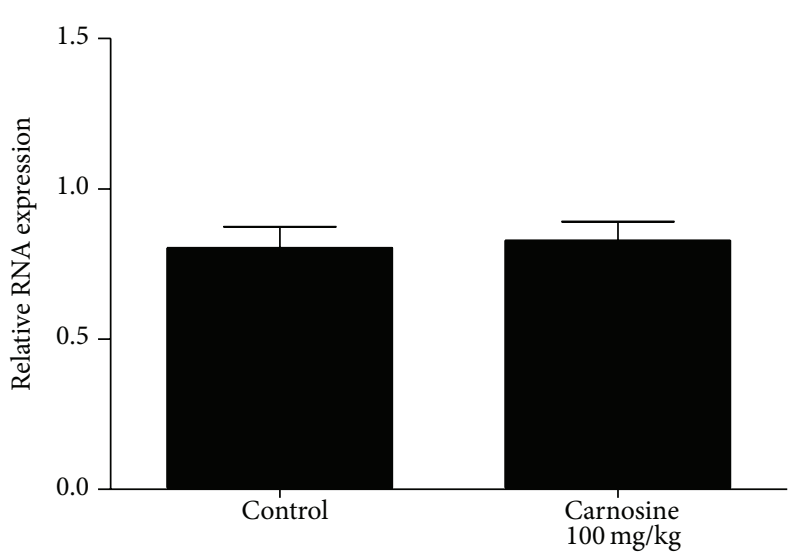

(a)

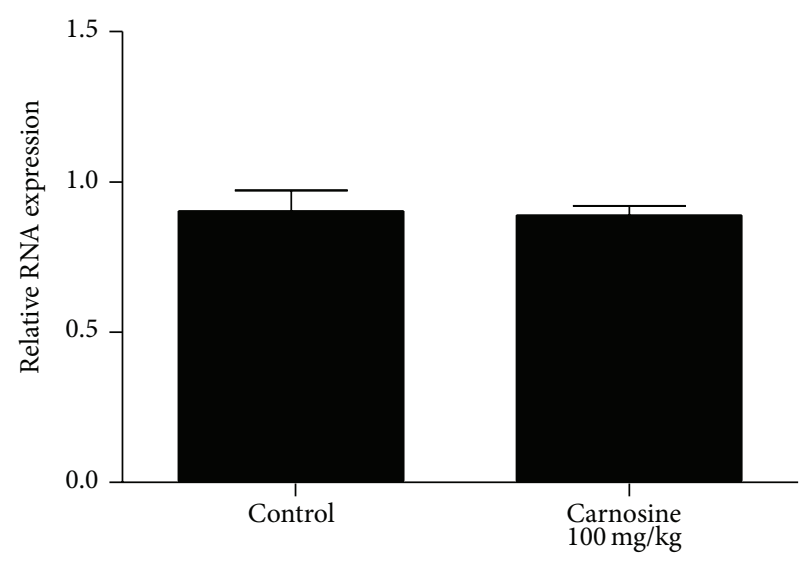

(b)

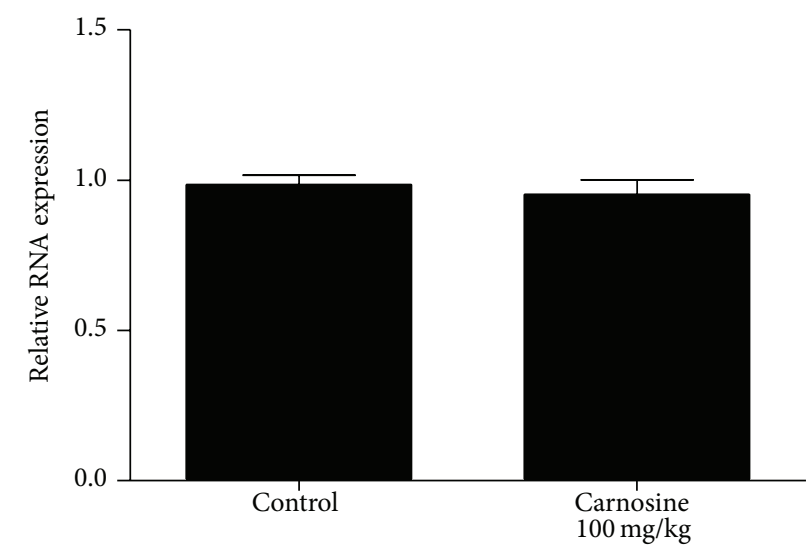

(c)

FIGURE 7: Effect of acute carnosine administration on relative mRNA expression of NRF-1 (a), PGC-1 $\alpha$ (b), and TFAM (c) activities in skeletal muscle of young rats. Results are mean \pm S.E.M. for four to six independent animals performed in quadruplicate. No significant difference between groups was detected.

The same pattern of alteration was also observed in malate dehydrogenase activity, which was found increased in rats receiving carnosine acutely and unaltered in animals receiving the dipeptide chronically. Thus, it may be proposed that skeletal muscle is able to adapt to high carnosine levels, recovering the impaired enzyme activities back to control conditions. A putative mechanism involved in such adaptation is increased mitochondrial synthesis, since the enzymes affected by carnosine administration present mitochondrial localization. Considering that carnosine administration increases vimentin synthesis [36] and that vimentin is a cytoskeleton protein that may be related to mitochondrial motility and localization [37], it is possible that this process is mediated by increased vimentin synthesis. However, data on NRF-1, PGC-1 $\alpha$, and TFAM mRNA levels suggest that carnosine interferes with these enzymatic activities through mechanisms unrelated to mitochondrial biogenesis, but the influence of carnosine on mitophagy cannot be ruled out.

At present, we cannot ascertain the pathophysiological relevance of our findings. In this communication, we induced carnosinemia in the animals by administering carnosine intraperitoneally. With respect to this fact, it should be mentioned that carnosine dietary administration elicits increase of its content in human skeletal muscle [38]. The carnosine levels in this tissue are situated within $30-50 \mathrm{mmol} / \mathrm{kg}$ of wet weight [39] and are prone to alterations according to diet, gender, and age of subject [40]. Additionally, in our study, carnosine is increased in skeletal muscle of rat, such as occurrence in patients with carnosinemia.

\section{Conclusion}

It is here shown that carnosine administration impairs electron transfer through the mitochondrial respiratory chain in skeletal muscle of young rats, without changing mitochondrial biogenesis-related transcription factors. At least in part, this finding does not corroborate some reports, which indicate that this dipeptide increases the efficiency and intensity of oxidative phosphorylation in rats adapted to hypobaric hypoxia [41]. The human carnosinase levels are almost undetectable in plasma of neonates, increasing according to aging [6], rendering young individuals less prone to metabolize carnosine. In case these findings are confirmed by further studies and ATP depletion is also observed, it is possible that an energy dysfunction, secondary to carnosine accumulation, may aid to explain some of muscle 


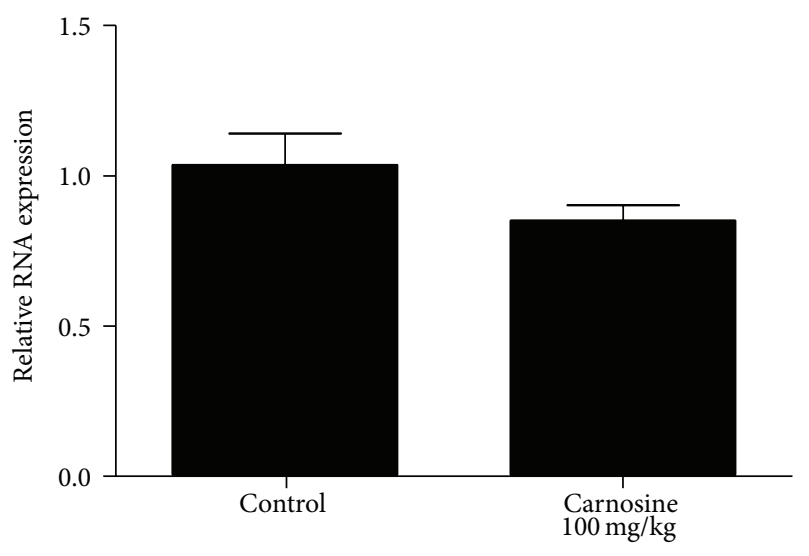

(a)

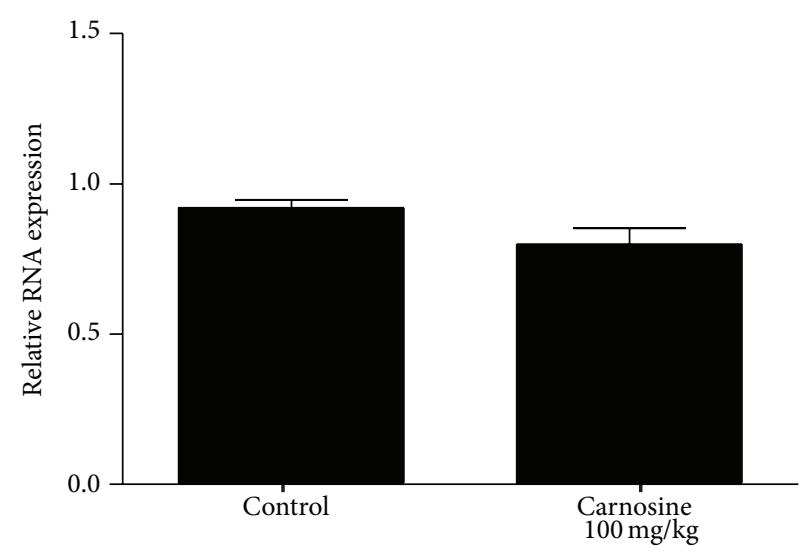

(b)

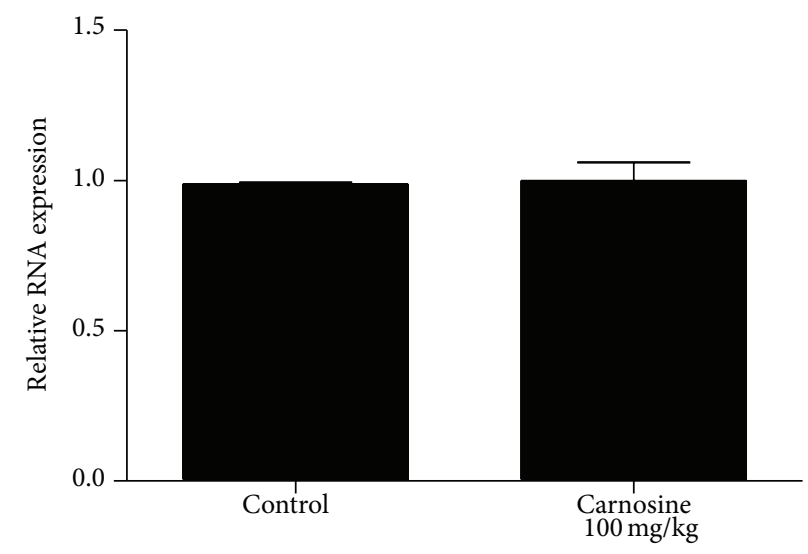

(c)

FIGURE 8: Effect of chronic carnosine administration on relative mRNA expression of NRF-1 (a), PGC-1 $\alpha$ (b), and TFAM (c) activities in skeletal muscle of young rats. Results are mean \pm S.E.M. for four to six independent animals performed in quadruplicate. No significant difference between groups was detected.

symptoms commonly observed in young patients with serum carnosinase deficiency.

\section{Conflict of Interests}

The authors declare that there is no conflict of interests regarding the publication of this paper.

\section{Acknowledgments}

This research was supported by resources from Universidade do Extremo Sul Catarinense and Brazilian National Council for Scientific and Technological Development (CNPq). Luiza Wilges Kist was recipient of fellowships from Coordenação de Aperfeiçoamento de Pessoal de Nível Superior (CAPES).

\section{References}

[1] L. Bonfanti, P. Peretto, S. de Marchis, and A. Fasolo, "Carnosinerelated dipeptides in the mammalian brain," Progress in Neurobiology, vol. 59, no. 4, pp. 333-353, 1999.

[2] W. Gulewitsch and S. Amiradzibi, "Ueber das carnosin, eine neue organische base des fleischextraktes," Berichte der
Deutschen Chemischen Gesellschaft, vol. 33, no. 2, pp. 1902-1903, 1900.

[3] K. Nagai and T. Suda, "Realization of spontaneous healing function by carnosine," Methods and Findings in Experimental and Clinical Pharmacology, vol. 10, no. 8, pp. 497-507, 1988.

[4] H. Abe, "Role of histidine-related compounds as intracellular proton buffering constituents in vertebrate muscle," Biochemistry, vol. 65, no. 7, pp. 757-765, 2000.

[5] S. Geissler, M. Zwarg, I. Knütter, F. Markwardt, and M. Brandsch, "The bioactive dipeptide anserine is transported by human proton-coupled peptide transporters," FEBS Journal, vol. 277, no. 3, pp. 790-795, 2010.

[6] J. F. Lenney, R. P. George, and A. M. Weiss, "Human serum carnosinase: characterization, distinction from cellular carnosinase, and activation by cadmium," Clinica Chimica Acta, vol. 123, no. 3, pp. 221-231, 1982.

[7] C. R. Scriver and K. M. Gibson, "Disorders of $\beta$ - and $\gamma$-amino acids in free and peptide-linked forms," in The Metabolic and Molecular Bases of Inherit, C. R. Scriver, A. L. Beaudet, S. Sly, and D. Valle, Eds., vol. 1, part 5, pp. 1349-1368, McGraw-Hill, New York, NY, USA, 7th edition, 1995.

[8] W. H. Murphey, D. G. Lindmark, and L. I. Patchen, "Serum carnosinase deficiency concomitant with mental retardation," Pediatric Research, vol. 7, no. 7, pp. 601-606, 1973. 
[9] H. Lunde, O. Sjaastad, and L. Gjessing, "Homocarnosinosis: hypercarnosinuria," Journal of Neurochemistry, vol. 38, no. 1, pp. 242-245, 1982.

[10] T. L. Perry, S. Hansen, B. Tischler, R. Bunting, and K. Berry, "Carnosinemia. A new metabolic disorder associated with neurologic disease and mental defect," The New England Journal of Medicine, vol. 277, no. 23, pp. 1219-1227, 1967.

[11] S. M. Willi, Y. Zhang, J. B. Hill, M. C. Phelan, R. C. Michaelis, and K. R. Holden, "A deletion in the long arm of chromosome 18 in a child with serum carnosinase deficiency," Pediatric Research, vol. 41, no. 2, pp. 210-213, 1997.

[12] B. E. Bonefeld, B. Elfving, and G. Wegener, "Reference genes for normalization: a study of rat brain tissue," Synapse, vol. 62, no. 4, pp. 302-309, 2008.

[13] Q. Zhang, Y. Wu, H. Sha et al., "Early exercise affects mitochondrial transcription factors expression after cerebral ischemia in rats," International Journal of Molecular Sciences, vol. 13, no. 2, pp. 1670-1679, 2012.

[14] A. H. V. Schapira, V. M. Mann, J. M. Cooper et al., "Anatomic and disease specificity of NADH CoQ1 reductase (complex I) deficiency in Parkinson's disease," Journal of Neurochemistry, vol. 55, no. 6, pp. 2142-2145, 1990.

[15] J. C. Fischer, W. Ruitenbeek, and J. A. Berden, "Differential investigation of the capacity of succinate oxidation in human skeletal muscle," Clinica Chimica Acta, vol. 153, no. 1, pp. 23-26, 1985.

[16] B. P. Hughes, "A method for the estimation of serum creatine kinase and its use in comparing creatine kinase and aldolase activity in normal and pathological sera," Clinica Chimica Acta, vol. 7, no. 5, pp. 597-603, 1962.

[17] P. F. Schuck, G. Leipnitz, C. A. J. Ribeiro et al., "Inhibition of creatine kinase activity in vitro by ethylmalonic acid in cerebral cortex of young rats," Neurochemical Research, vol. 27, no. 12, pp. 1633-1639, 2002.

[18] G. B. Kitto, "Intra- and extramitochondrial malate dehydrogenases from chicken and tuna heart," Methods in Enzymology, vol. 13, pp. 106-116, 1969.

[19] O. H. Lowry, N. J. Rosebrough, A. L. Farr, and R. J. Randall, "Protein measurement with the Folin phenol reagent," The Journal of Biological Chemistry, vol. 193, no. 1, pp. 265-275, 1951.

[20] J. Drozak, M. Veiga-da-Cunha, D. Vertommen, V. Stroobant, and E. van Schaftingen, "Molecular identification of carnosine synthase as ATP-grasp domain-containing protein 1 (ATPGD1)," The Journal of Biological Chemistry, vol. 285, no. 13, pp. 9346-9356, 2010.

[21] P. J. Quinn, A. A. Boldyrev, and V. E. Formazuyk, "Carnosine: its properties, functions and potential therapeutic applications," Molecular Aspects of Medicine, vol. 13, no. 5, pp. 379-444, 1992.

[22] P. S. Manhiani, J. K. Northcutt, I. Han, W. C. Bridges, and P. L. Dawson, "Antioxidant activity of carnosine extracted from various poultry tissues," Poultry Science, vol. 92, no. 2, pp. 444453, 2013.

[23] G. Aldini, M. Orioli, G. Rossoni et al., "The carbonyl scavenger carnosine ameliorates dyslipidaemia and renal function in Zucker obese rats," Journal of Cellular and Molecular Medicine, vol. 15, no. 6, pp. 1339-1354, 2011.

[24] G. Vistoli, D. de Maddis, V. Straniero et al., "Exploring the space of histidine containing dipeptides in search of novel efficient RCS sequestering agents," European Journal of Medicinal Chemistry, vol. 66, pp. 153-160, 2013.
[25] Z. Xie, S. P. Baba, B. R. Sweeney, and O. A. Barski, "Detoxification of aldehydes by histidine-containing dipeptides: from chemistry to clinical implications," Chemico-Biological Interactions, vol. 202, no. 1-3, pp. 288-297, 2013.

[26] A. R. Hipkiss, "Aging, proteotoxicity, mitochondria, glycation, $\mathrm{NAD}^{+}$and carnosine: possible inter-relationships and resolution of the oxygen paradox," Frontiers in Aging Neuroscience, vol. 2, article 10, 2010.

[27] A. R. Hipkiss, "Energy metabolism, proteotoxic stress and age-related dysfunction - Protection by carnosine," Molecular Aspects of Medicine, vol. 32, no. 4-6, pp. 267-278, 2011.

[28] A. R. Hipkiss, S. P. Cartwright, C. Bromley, S. R. Gross, and R. M. Bill, "Carnosine: can understanding its actions on energy metabolism and protein homeostasis inform its therapeutic potential?" Chemistry Central Journal, vol. 7, no. 1, article 38, 2013.

[29] M.-C. Mong, C.-Y. Chao, and M.-C. Yin, "Histidine and carnosine alleviated hepatic steatosis in mice consumed high saturated fat diet," European Journal of Pharmacology, vol. 653, no. 1-3, pp. 82-88, 2011.

[30] D. Mizuno and M. Kawahara, "The molecular mechanisms of zinc neurotoxicity and the pathogenesis of vascular type senile dementia," International Journal of Molecular Sciences, vol. 14, no. 11, pp. 22067-22081, 2013.

[31] A. Asperger, C. Renner, M. Menzel, R. Gebhardt, J. Meixensberger, and F. Gaunitz, "Identification of factors involved in the anti-tumor activity of carnosine on glioblastomas using a proteomics approach," Cancer Investigation, vol. 29, no. 4, pp. 272-281, 2011.

[32] L. A. Bharadwaj, G. F. Davies, I. J. Xavier, and N. Ovsenek, "Lcarnosine and verapamil inhibit hypoxia-induced expression of hypoxia inducible factor (HIF-1 $\alpha$ ) in H9c2 cardiomyoblasts," Pharmacological Research, vol. 45, no. 3, pp. 175-181, 2002.

[33] E. Ito-Kato, N. Suzuki, M. Maeno et al., "Effect of carnosine on runt-related transcription factor-2/core binding factor $\alpha-1$ and Sox9 expressions of human periodontal ligament cells," Journal of Periodontal Research, vol. 39, no. 3, pp. 199-204, 2004.

[34] V. Calabrese, C. Colombrita, E. Guagliano et al., "Protective effect of carnosine during nitrosative stress in astroglial cell cultures," Neurochemical Research, vol. 30, no. 6-7, pp. 797-807, 2005.

[35] K. M. Soliman, M. A. Hamed, and S. A. Ali, "Hepatoprotective effect of carnosine on liver biochemical parameters in chronic ethanol intoxicated rat," The Medical Journal of the Islamic World Academy of Sciences, vol. 16, no. 2, pp. 77-86, 2006.

[36] D. Ikeda, S.-I. Wada, C. Yoneda, H. Abe, and S. Watabe, "Carnosine stimulates vimentin expression in cultured rat fibroblasts," Cell Structure and Function, vol. 24, no. 2, pp. 79-87, 1999.

[37] O. E. Nekrasova, M. G. Mendez, I. S. Chernoivanenko et al., "Vimentin intermediate filaments modulate the motility of mitochondria," Molecular Biology of the Cell, vol. 22, no. 13, pp. 2282-2289, 2011.

[38] C. Sale, B. Saunders, and R. C. Harris, "Effect of beta-alanine supplementation on muscle carnosine concentrations and exercise performance," Amino Acids, vol. 39, no. 2, pp. 321-333, 2010.

[39] A. A. Boldyrev and S. E. Severin, "The histidine-containing dipeptides, carnosine and anserine: distribution, properties and biological significance," Advances in Enzyme Regulation, vol. 30, pp. 175-188, 1990.

[40] I. Everaert, A. Mooyaart, A. Baguet et al., "Vegetarianism, female gender and increasing age, but not CNDP1 genotype, 
are associated with reduced muscle carnosine levels in humans," Amino Acids, vol. 40, no. 4, pp. 1221-1229, 2011.

[41] V. N. Korobov, N. M. Doliba, and I. V. Telegus, "Carnosine in adaptation to hypobaric hypoxia," Biokhimiya, vol. 58, no. 5, pp. 740-744, 1993. 

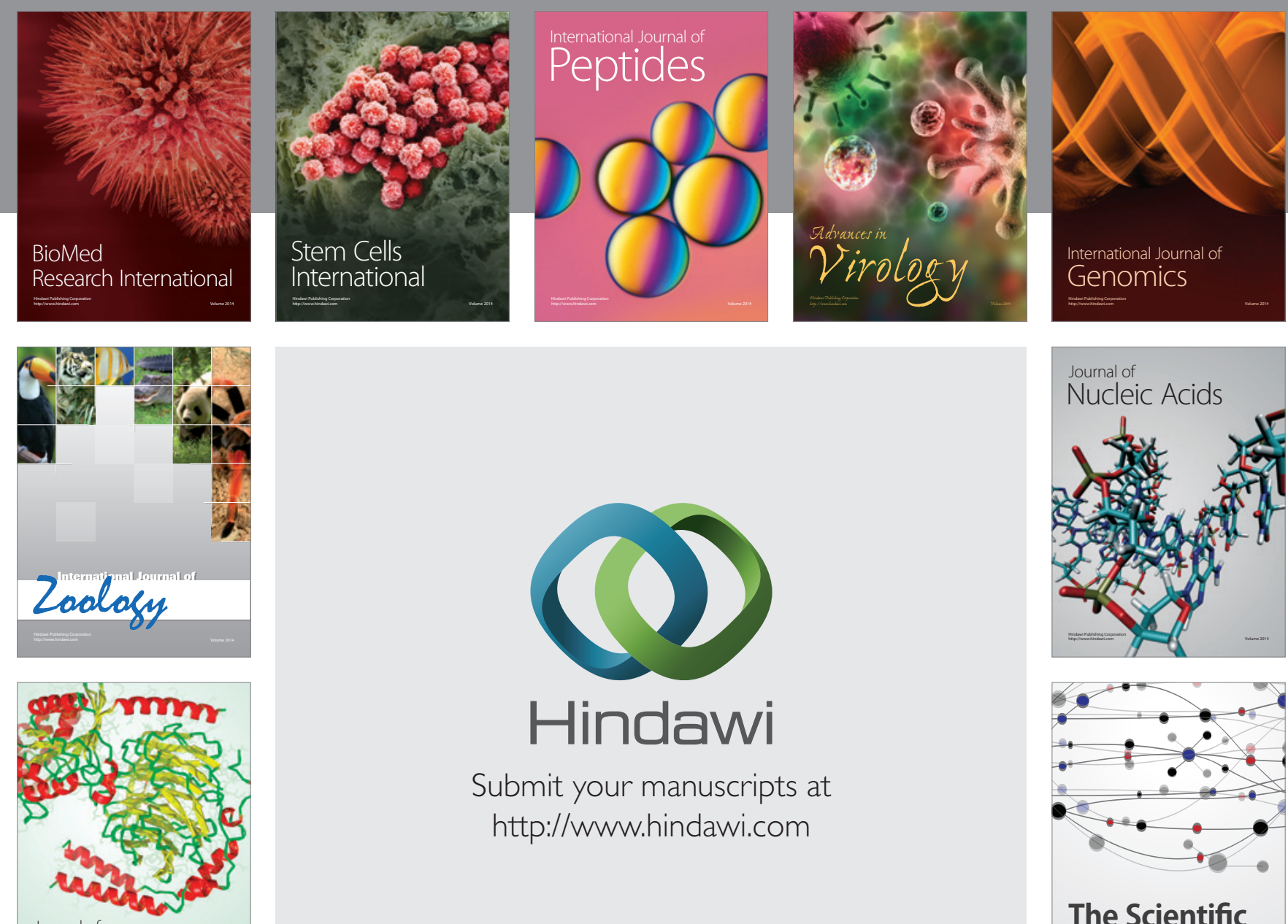

Submit your manuscripts at

http://www.hindawi.com

Journal of
Signal Transduction
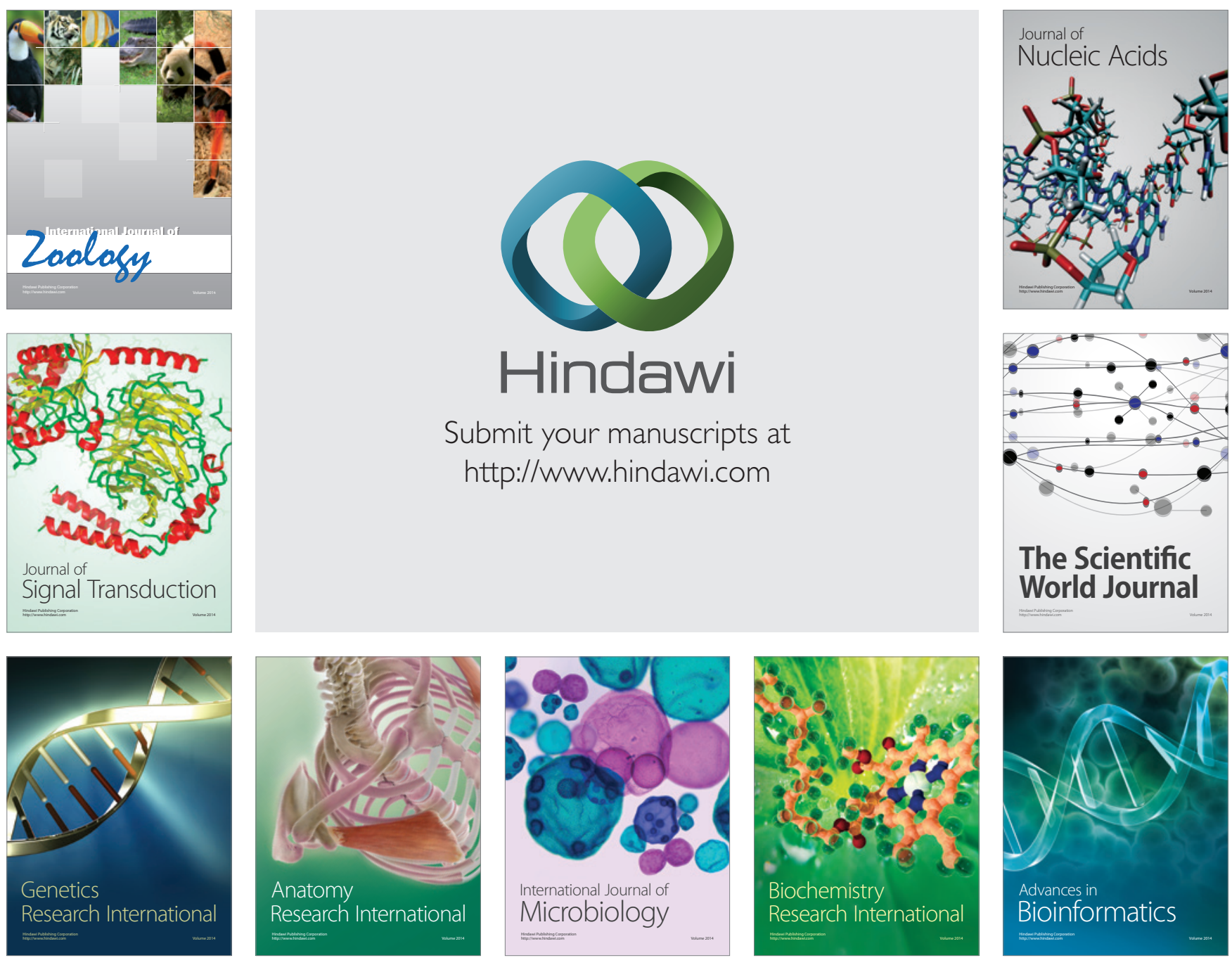

The Scientific World Journal
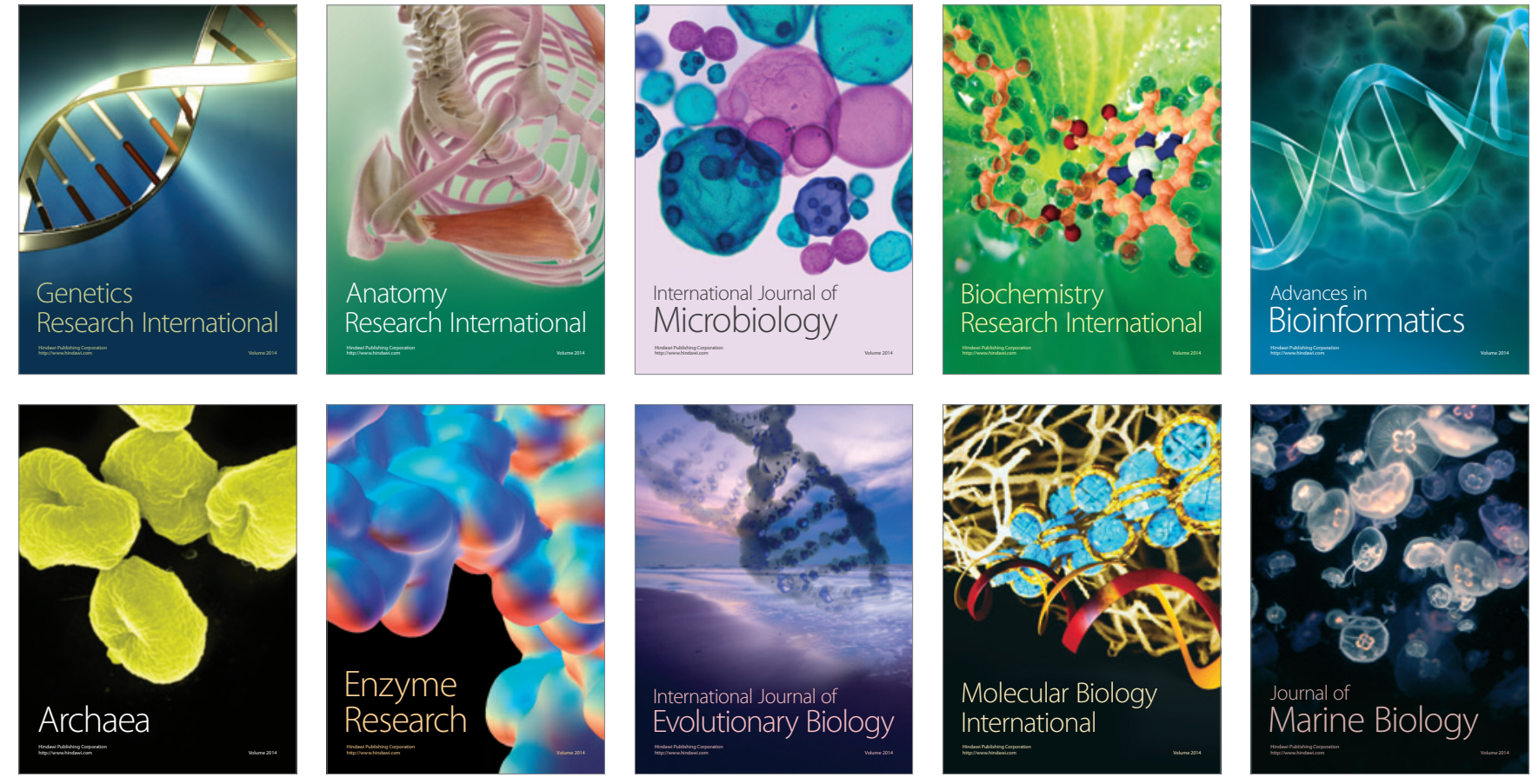